\title{
Earlier identification of biliary atresia and hepatobiliary disease: selective screening in the third week of life
}

\author{
Alex P Mowat, L L Davidson, M C Dick
} The possibility of screening for biliary atresia
has emerged as a controversial issue $\mathrm{e}^{1-6}$ in the wake of Yellow Alert, an educational programme launched in May 1993, by the Children's Liver Disease Foundation with the help of the Department of Health, in order to improve the outcome of hepatobiliary disease in infants. The aim of that campaign is to make certain that all babies who remain jaundiced after two weeks of age are tested for conjugated hyperbilirubinaemia and referred for timely specialist investigation and treatment if positive. Such infants most commonly have disorders other than biliary atresia for which early and specific treatment is equally desirable. All have vitamin $\mathrm{K}$ malabsorption and are at special risk of life threatening bleeding or brain damage from vitamin $\mathrm{K}$ responsive haemorrhagic disease, a risk that will almost certainly be increased by the decline in the use of parenteral vitamin $\mathrm{K}$ in the newborn. ${ }^{7} \mathrm{We}$ welcome the interest as an opportunity to achieve a consensus that can be implemented nationally on how best to ensure early identification and referral for diagnosis and treatment of infants with biliary atresia and other hepatobiliary disorders starting in the first weeks of life.

The main issues raised with respect to screening for biliary atresia are whether the condition is sufficiently important to merit treatment and whether earlier treatment is so much better than late that it satisfies criteria for inclusion in a screening programme. If it is, should screening be delayed to 21 days of age to be more cost effective and create less parental anxiety?

As screening involves seeking out and testing the whole population, we maintain that assessing persistent jaundice in the neonatal period might be considered selective screening or more correctly case finding, that is, evaluating to detect disease and bring patients to treatment. The incidence of biliary atresia is between one in 10000 and one in 20000 infants, ${ }^{8}$ while the incidence of all causes of neonatal liver disease presenting with jaundice is at least four times as high, ${ }^{9}$ and is sufficient to justify selective screening. In our opinion there have been sufficient observations on the beneficial effects of early detection to support the need for an early case finding programme for some years.
Biliary atresia, a condition of unknown but probably diverse cause, ${ }^{10}$ is characterised by a progressive sclerosing cholangiopathy which causes complete obstruction of the extrahepatic bile ducts and early death from biliary cirrhosis. Many experienced centres with an expert surgeon have demonstrated that surgery after 60 days of age reduces the serum bilirubin to normal concentrations in only $20-35 \%$ of infants; with surgery before 60 days over $80 \%$ became jaundice free. ${ }^{11-14}$ One group has achieved even better results in those having surgery by 45 days of age. ${ }^{15}$ By 1991, it had been documented that the 15 year survival in infants who became jaundice free after surgical correction of biliary atresia was $87 \%{ }^{16}$ Seventy per cent had no medical problems and were leading entirely normal lives. Without successful surgery infants with biliary atresia die at a mean age of approximately 1 year (a few survive until 7 years) unless treated with liver transplantation. With one year survival rates after one or more transplantation procedures approaching $90 \%,{ }^{17}$ lifer transplantation is a mode of treatment currently offered by the NHS for children in whom portoenterostomy has been unsuccessful. Liver transplantation requires many more resources than portoenterostomy and has more medical and surgical complications. ${ }^{17-19}$ The patient needs lifelong immunosuppressive treatment. Thus although biliary atresia is the most common indication for liver transplantation in childhood, its role in biliary atresia is secondary to that of portoenterostomy. ${ }^{19}$

Despite intensive professional education in the last 15 years ${ }^{811-1320-23}$ over $50 \%$ of children with biliary atresia are referred after 6 weeks of age. ${ }^{8}$ Even now half still come to surgery too late for optimum results. ${ }^{24}$ To promote earlier recognition a number of recommendations were made, ${ }^{8}$ which were included in a list of desirable standards of care in the 1993 British Paediatric Association (BPA) publication on medical audit. These included the need to test for conjugated hyperbilirubinaemia in all infants who remain even mildly jaundiced after 14 days of age, the latter being supported by two subsequent reviews. ${ }^{2526}$ At 15 days of age the infant with biliary atresia has mild jaundice but is likely to be otherwise well and the sclerosing process is 
unlikely to have caused irreversible damage. By the time complications appear the deadline for effective surgery will have passed for the majority of infants.

Logan and Stanton ${ }^{3}$ raised the question as to whether what they describe as a programme of screening for biliary atresia satisfied the criteria for a screening policy as defined by Wilson and Junger. ${ }^{27}$ The principles these authors advocate in determining if a condition merits screening (pages 14-40) are, as detailed below, fulfilled for biliary atresia. Biliary atresia is an important public health problem, both for the individual infant and family and for the community because of its cost. There is an accepted form of treatment that dramatically improves the outcome when applied before 60 days and is even better before 45 days of age. We do, in the UK, have facilities for diagnosis and treatment. There is a clearly recognised latent or early symptomatic state. There is a very suitable test for hepatobiliary disorders - that is, the detection of conjugated hyperbilirubinaemia, an always pathological finding. Absence of yellow or green pigment in consecutive stools over the course of two or three days is an extremely important but not pathognomonic sign in jaundiced infants. Such infants require urgent investigation to ascertain whether biliary atresia is present. Note that in some cases the stool does contain bile pigment in the first weeks of life before atresia is complete. ${ }^{9}$

Among infants with conjugated hyperbilirubinaemia associated with infective, metabolic, endocrine, haematological, or surgical disorders other than biliary atresia there are disorders that need to be identified and the infant given specific treatment as early as possible for maximum benefit. ${ }^{232829}$ In all of these conditions and in the cryptogenic or idiopathic variety of hepatitis that ultimately has a good long term prognosis, there may be a life threatening complication, namely late onset vitamin $K$ responsive haemorrhagic disease, occurring between 3 and 8 weeks of age. Around 50\% die or develop permanent severe neurological damage from intracranial haemorrhage. ${ }^{30-32}$ Tests for conjugated hyperbilirubinaemia are no more invasive than the tests for phenylketonuria or hypothyroidism that are included in infant surveillance programmes in nearly every country with a developed health care system. These tests would be performed only in babies who are jaundiced after 14 days of age. As all babies are already visited by both midwives and health visitors in the early weeks of life $^{2}$ the costs would be limited to that of training midwives and health visitors to recognise jaundice, the urine or laboratory tests, and tracking the results.

Clinical identification of jaundice must be the responsibility of the community paediatricians and the primary care team, and should be part of training for health visitors and/or midwives. Persistently jaundiced infants require testing for bilirubin in the urine and raised direct (conjugated) bilirubin in serum; this is no more than good clinical practice. The difficulty in the UK, at present, is that referral of a significant number of infants with conjugated hyperbilirubinaemia still occurs too late for optimum treatment.

To be most specific and cost effective screening for conjugated hyperbilirubinaemia should be performed at an age sufficiently young to prevent complications and to maximise benefits from specific treatment but delayed until most cases of benign jaundice have resolved. The published data suggest this to be after 8 days of age. Jaundice was present in only $2.4 \%$ in approximately 500 breast fed babies and none of 400 bottle fed babies examined at 3 weeks of age $\left(1.3 \%\right.$ of total cohort). ${ }^{33}$ In the hyperbilirubinaemia study, to which the commentary refers, ${ }^{34}$ a transcutaneous jaundice meter was used to assess jaundice in 140 infants ( 76 breast fed). The main conclusion was that the pattern of jaundice in breast fed infants follows a bimodal fashion. Approximately $75 \%$ had meter readings similar to those of bottle fed infants reaching baseline concentrations at 8 days but $25 \%$ had readings that were both higher and more prolonged. The mean concentrations were still raised in these breast fed infants when the study ended at 21 days of age. Hence the recommendation to screen for jaundice after 14 days was a compromise to minimise unnecessary testing while referring infants with conjugated hyperbilirubinaemia when treatment is most likely to prevent chronic disability.

We look forward with interest to more details of the methodology of the unpublished study by Stanton (referred to in Logan and Stanton ${ }^{3}$ ) in which jaundice was reported by health visitors in $17 \cdot 7 \%$ of infants at 12 to 14 days. Their observations would suggest that a large number of children with benign jaundice would be tested. We need to know the prevalence of persistent jaundice in babies, both benign and conjugated, at 14 and 21 days. A study to determine the most appropriate time to test the urine for bilirubin or measure the serum direct bilirubin ought to be planned and funded. The only estimate of the incidence of conjugated hyperbilirubinaemia in the UK, one in 2500 live births, was found in an epidemiological study that identified infants who came to the attention of paediatricians and had conjugated hyperbilirubinaemia that lasted at least two weeks. ${ }^{9}$ In that study the incidence of biliary atresia was one in 12200 live births. The current BPA surveillance unit's study of biliary atresia will update the incidence in the UK.

Major cash savings, as well as improved health, should occur with early detection of hepatobiliary disease. There should be a fall in the incidence of vitamin $K$ responsive late onset haemorrhagic disease of the newborn (4.4 per 100000 live births in UK). ${ }^{30}$ Between 40 to $85 \%$ were jaundiced due to underlying liver disease that was untreated and/or investigated until the bleeding occurred ${ }^{31}{ }^{32}$; the bleeding is often intracranial. Three such cases admitted to our unit in the last 12 months are likely to have permanent brain damage. The number of children requiring liver transplantation should fall. Suppose, for example, each additional liver transplant in a large service 
costs $£ 30000$, this would be saved for each child not requiring a transplant. This is a minimal estimate of the cost that disounts the ongoing cost of medical and surgical care and immunosuppressive drug treatment that may cost an estimated $£ 1000$ per case per year. If it involved the development of a specialised paediatric liver unit with liver transplantation facilities the cost would be perhaps $£ 100000$ per case. In the USA the cost for one infant was $\$ 200000$ in the first year. ${ }^{35}$ If the incidence of biliary atresia is as low as one in 20000 live births, and through effective screening an additional 10 children received effective, timely, surgical intervention and did not require transplantation, the NHS would save more than $£ 300000$ each year; if the incidence is one in 12000 live births, more than $£ 480000$ would be saved per year. The savings produced by the reduction in the incidence of chronic mental handicap caused by intracranial bleeding and earlier diagnosis of other treatable hepatobiliary disorders and prevention of complications would be an additional bonus.

We have estimated the cost for the case finding programme, using the model offered by Logan and Stanton, assuming a range of prevalence rates for persistent jaundice from $1 \cdot 3$ to $10 \%$. We have assessed the cost of urine collecting bags at $£ 1$ each, urine testing strips impregnated with bilirubin detecting chemicals at $20 \mathrm{p}$ each, and the health visitor's time in collecting a sample at $£ 5$. We have assumed that in $50 \%$ of infants, the urine will be negative for bilirubin or unobtainable. The sensitivity and specificity of these strips in detecting conjugated jaundice ${ }^{36}$ is established in the newborn but is the subject of an ongoing study in older infants. The laboratory test for direct bilirubin costing $£ 3.50$ would be required. We have assumed that tracking results would take two telephone calls at five minutes each for each child. If the prevalence of jaundice is $10 \%$ the cost of the proposed screening programme will be an estimated $£ 434000$. If the prevalence of persistent jaundice was $1 \cdot 3 \%$, the cost will be an estimated $£ 56380$.

There is conclusive evidence that long term outcome for children with biliary atresia can be much improved by its earlier identification, the essential criterion for inclusion in a screening programme. ${ }^{3738}$ Even if the cost exceeds savings, we consider that it is essential to implement this case finding programme now, particularly as more infants are likely to have had no parenteral vitamin $K$, and there seems to be a move by family doctors to postpone the age at well baby review from 6 to 8 weeks of age to coincide with immunisation. Midwives, health visitors, and other members of the primary health care team must identify all babies who remain jaundiced after 14 days of age, obtain urine and blood for bilirubin testing, and refer immediately for further investigations those with conjugated hyperbilirubinaemia. Community paediatricians should take responsibility for implementing and evaluating this task.
1 MacKinlay GA. Jaundice persisting beyond 14 days of age. BMF 1993; 306: 1426-7.

2 Close $C$. Health visitors should assess jaundice in babies. BMF 1993; 307: 260.

3 Logan S, Stanton A. Screening for biliary atresia. Lancet 1993; 324: 256 .

4 MacFaul R. Screening for biliary atresia. Lancet 1993; 342: 811 .

5 Mowat AP, Davidson LL, Dick MC. Screening for biliary atresia. Lancet 1993; 342: 1234-5.

6 Arkley CM. Screening for biliary atresia. Lancet 1993; 342. 1235.

7 Klebanoff HJ, Read JS, Mills JL, Shiono PH. The risk of childhood cancer after neonatal exposure to vitamin K. $N$ Engl f Med 1993; 329: 905-8.

8 Hussain M, Howard ER, Mieli-Vergani G, Mowat AP Jaundice at 14 days of age: exclude biliary atresia. Arch $D i s$ Child 1991; 66: 1177-9.

9 Dick MC, Mowat AP. Hepatitis syndrome in infancy - an epidemiological study with 10 year follow up. Arch $D$ is Child 1985; 60: 512-6.

10 Silvera TR, Salzano FM, Howard ER, Mowat AP. Congenital structural abnormalities in biliary atresia: evidence for etiopathogenic heterogeneity and therapeutic implications. Acta Paediatr Scand 1991; 80: 1192-9.

11 McClement J, Howard ER, Mowat AP. Results of surgical treatment for extrahepatic biliary atresia in United treatment for extrahepatic biliary atresia

12 Anonymous. Long term survival in biliary atresia. Lancet 1989; ii: 597-8.

13 Howard ER. Extrahepatic biliary atresia. In: Blumgart LH ed. Surgery of the liver and biliary tract. Edinburgh Churchill Livingstone, 1988: 707-22.

14 De Conti RW, Craver RD, Willis GW, Hill CB, Hayes DH Arensman RM. Extrahepatic biliary atresia from diagnosis to liver transplantation. Pediatric Surgery International 1992; 7: 737-40.

15 Gautier F, Laurent J, Bernard O, Valayer J. Improvement of results after Kasai operation. The need for early diagnosis and surgery. 5th International Sendai symposium on biliary atresia. Japan: Professional Postgraduate Services, 1991: atresia. Jap.

16 Ohi R, Nio $M$, Chiba T, Endo N, Goto $M$, Ibrahim $M$ Long-term follow-up after surgery for patients with biliary atresia. F Pediatr Surg 1990; 25: 442-5.

17 Beath SV, Brook GD, Kelly DA, et al. Successful liver transplantation in babies under 1 year. BMF 1993; 307: 825-8.

18 Salt A, Noble-Jamieson G, Barnes ND, et al. Liver transplantation in 100 children: the Cambridge and King's College Hospital series. $B M \mathcal{F}$ 1992; 304: 416-21.

19 Chiyende J, Mowat AP. Liver transplantation in children. Arch Dis Child 1992; 67: 1124-7.

20 Howard ER, Mowat AP. Extrahepatic biliary atresia. Recent developments in management. Arch Dis Child 1977; 52: 825-7.

21 Mieli-Vergani G, Howard ER, Portmann B, Mowat AP. Late referral for biliary atresia - missed opportunities for effective surgery. Lancet 1989; i: 421-3.

22 Nelson R. Managing biliary atresia. Referral before 6 weeks is vital. $B M \mp 1989 ; 298: 1471$.

23 Mowat AP. Hepatitis and cholestasis in infancy: intrahepatic disorders. Liver disorders in childhood. 2nd Ed. London: Butterworths, 1987: 37-71.

24 British Paediatric Association Surveillance Unit. Newsletter. London: BPA, November 1993.

25 Newman TB, Maisels MJ. Evaluation and treatment of jaundice in the term newborn: a kinder, gentler approach. Pediatrics 1992; 89: 809-19.

26 Dodd KL. Neonatal jaundice - a lighter touch. Arch Dis Child 1993; 68: 529-32.

27 Wilson JMG, Jungner G. Principles and practice of screening for disease. Geneva: World Health Organisation, 1968.

28 Setchell KDR, Piccoli D, Heubi J, Balistereri WF. Inborn errors of bile acid metabolism. In: Lentze MJ, Reichen J, errors of bile acid metabolism. In: Lentze MJ, Reichen J, eds. Paediatric cholestasis. Novel approaches to treatm

29 Lindstedt S, Holme E, Lock EA, Hjalmarson O, Strandvik B. Treatment of hereditary tyrosinaemia by inhibition of 4-hydroxyphenyl-pyruvate dioxygenase. Lancet 1992 340: 813-7.

30 McNinch AW, Tripp JH. Haemorrhagic disease of the newborn in the British Isles: two year prospective study. $B M \mathcal{F}$ 1991; 303: 1105-8.

31 Ekeland $H$. Late haemorrhagic disease in Sweden 1987-89. Acta Paediatr 1991; 80: 966-8.

32 Sutor AH, Dagres N, Niederhoff H. Vitamin-K-Mangelblutungen in Deutschland. Hamostaseologie 1992; 12: 116-26.

33 Winfield $C R$, MacFaul R. Clinical study of prolonged jaundice in breast- and bottle-fed babies. Arch Dis Child 1978 53: $506-7$.

34 Kivlahan C, James EJP. The natural history of neonatal jaundice. Pediatrics 1984; 74: 364-70.

35 Whittington PF, Balistreri WF. Liver transplantation in pediatrics: indications, contraindications and pretranspediatrics: indications, contraindications and

36 Newman TB, Hope S, Stevenson DK. Direct bilirubin measurement in jaundiced term newborns. A re-evaluation. surement in jaundiced term newbon

37 Cochrane AL, Holland WW. Validation of screening procedures. Br Med Bull 1971; 27: 3-8.

38 Holland WW. Screening: reasons to be cautious. $B M F$ 1993; 306: 1222-3. 